II on abdominal segments III, IV, V and VI prominent, black. Beneath green with a pair of small black warts on the rear of abdominal segments. Length $16 \mathrm{~mm}$.

Stage IV.

Head yellowish marbled with brown. Body green or yellow-green, in some cases much marbled with brown; lateral purple stripe prominent only on anteriorand posterior segments where it is marbled with white; black lateral dots as before; black dorsal tubercles also present, especially prominent on abdominal segment III, where they form more or less raised warts; claspers striped with purplish, being the continuation of the lateral stripe. Two small black tubercles on posterior margin of segments underneath. Length $25 \mathrm{~mm}$.

Stage $V$.

Very variable in ground color and markings. The majority have pale green head, marbled with brown; body olive green with no traces of stripes; mesothorax swollen, with reddish-purple lateral wart, shaded inferiorly with lighter, this color being continued forward to the head. Third abdominal segment with two prominent dorsal red-brown warts, more or less confluent, and two lateral ones, all situated on posterior portion of segment; similar dorsal warts on 6th abdominal. Rear segments shaded with purple brown; lateral dots of previous stages almost or wholly lacking; tubercle II of abdominal segments also much less marked with black. Beneath green with two reddish warts in medio-ventral region of $2 \mathrm{~d}$ abdominal segment.

Other larvæ are generally much browner in appearance, due to geminate dorsal, subdorsal and lateral lines filled in with brown, but much broken and irregular. Beneath markings of dorsal surface repeated; all tubercles and warts more prominently marked than in the green form of larva; tubercles frequently arisefrom a small white patch, being themselves black; tubercle II of 4th and 5 th abdominal segments often reddish, more or less prominent. Length full grown $37 \mathrm{~mm}$.

Pupa. Light brown, strongly marked with olivaceous and darker shades of brown; antennæ and leg sheaths darker; wing cases with numerous small grooves, giving a general sponge-like appearance. Spiracles dark brown; segmental incisions banded with dark brown; cremaster with two strong hooks.

Food plant. Quercus.

The species is double-brooded, the first specimen emerging 52 days from date of oviposition.

\title{
A NEW SPECIES OF PSELLIOPUS (MILYAS).
}

\author{
By Wm. T. Davis, \\ Staten Island, New York.
}

While in quest of insects in the country to the west of Beltsville, Prince George Co., Maryland, on September 26, 1911, with Mr. Frederick Knab and Mr. Clarence R. Shoemaker, I observed that 
the specimens of Milyas or Pselliopus that I saw were unusually orange in color. They were also quite plentiful and a pair was observed in copulation. Upon comparing the specimens collected with the darker colored Pselliopus cinctus Fabr. in my collection from Long Island, N. Y.; New Jersey; Pennsylvania; Virginia and Washington, D. C., it was observed that, in addition to color differences, the humeral angles were not the same. I communicated these facts to Mr. Harry G. Barber, who has been my chief guide in things Hemipterous, and he has kindly given the insects more study and has pointed out some other differences. The description of cinctus by Fabricius will cover both species, but we may consider it to be the darker and somewhat smaller form. From this, the new species which I take pleasure in naming after my friend, may be separated as follows:

\section{Pselliopus barberi sp. nov.}

Color. Anterior lobe of pronotum with black markings usually absent or reduced to two faint oblique streaks at anterior portion. Posterior lobe marked as in cinctus. Scutellum with no prominent black markings, which are either absent entirely or reduced to a small spot or to two faint oblique bands at extreme anterior part between the two whitish pruinose spots. Corium unmarked with black; orange yellow. Connexivum banded with black as in cinctus. Venter with black markings arranged much the same, but considerable variation occurs in both species. Markings of the legs, rostrum and antenna are similar, but the head has less amount of black maculation in barberi.

Structural differences. In cinctus the short, black tipped, acute spine, before the rounded humeral angle projects beyond the humeri and is directed slightly backward, while in barberi the black tipped spine preceding the humeral angle, is shorter, more obtuse and directed more laterally. It never extends beyond the humeral angle. Basal margin of the pronotum in front of the scutellum is feebly bisinuate in cinctus, while in barberi it is straight across. Scutellum of barberi is not so foliaceus and flat as in cinctus and a well defined ridge or keel runs backward from the transverse crescentic ridge. Apex of last genital segment of male with a very short, blunt erect spine in cinctus. Last genital segment of male in barberi armed with a long very pointed simple spine, which is directed obliquely forward and somewhat concealed. The inner genital lobes on either side of this are not produced in barberi or in cinctus as in zebra. In zebra the apex of the last genital segment of male is produced in the middle and armed with a sulcate pointed spine.

In addition to the type locality mentioned above, specimens of barberi have been examined from Great Falls, Va., Langdon, Mo., Kansas, and Austin, Tex. 


\section{SECOND INTERNATIONAL CONGRESS OF ENTOMOLOGY.}

The Second International Congress of Entomology will be held at Oxford, England, from August 12th to 17th, 1912. Futher particulars will be announced shortly. The executive committee proposes to find for members of the congress lodgings in the town, or in rooms in one of the colleges at a moderate charge; rooms in the colleges will be available only for men. The executive committee invites an early provisional notice of intention to join the congress, in order to make the arrangements for the necessary accommodation. The proceedings of the First Congress have just been published.

All communications and inquiries should be addressed to Malcolm Burr, Esq., care Entomological Society of London, 11 Cavendish Square, London, W., England.

Henry Skinner, Member Permanent Executive Committee representing America.

\section{THE WASHINGTON MEETING OF THE ENTOMO- LOGICAL SOCIETY OF AMERICA.}

The sixth annual meeting of the Entomological Society of America was held in Room 376 of the new United State National Museum Building on Tuesday and Wednesday, December 26 and 27.

The following papers were read:

Herbert Osborn.-Faunistic studies in entomology.

E. P. Felt.-Numerals as aids in classification.

E. S. Tucker.-Studies of insects bred and collected from the American mistletoe. Presented by Andrew Rutherford.

H. C. Severin.-The influence of temperature on the moulting of the walking-stick, Diapheromera femorata. (Title only.)

R. Matheson and C. R. Crosby.-Notes on aquatic Hymenoptera. Presented by C. R. Crosby.

Ann H. Morgan.-Photographs illustrating the life histories of May-flies.

H. Y. Tsou.-The Chinese wax-scale. 

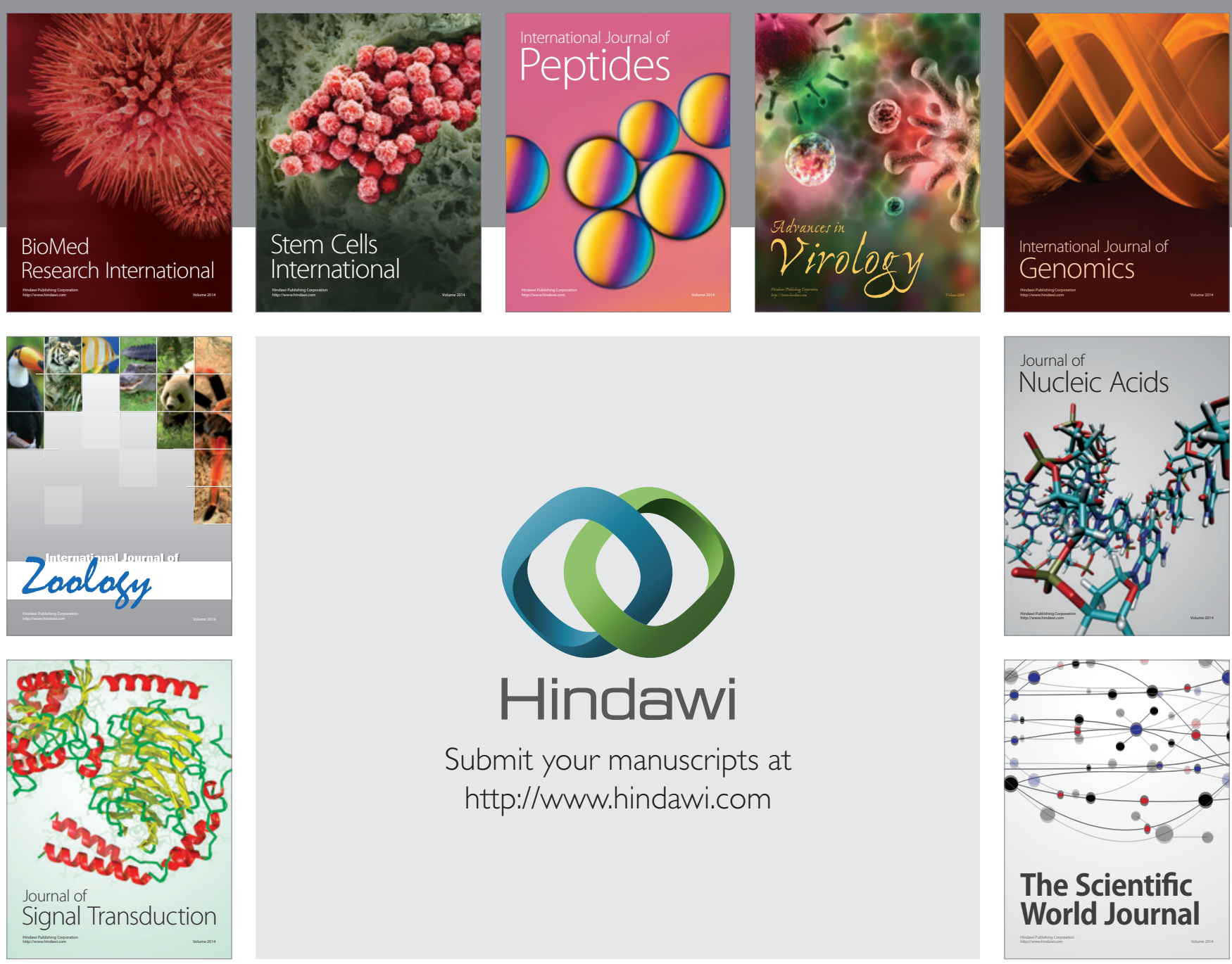

Submit your manuscripts at

http://www.hindawi.com
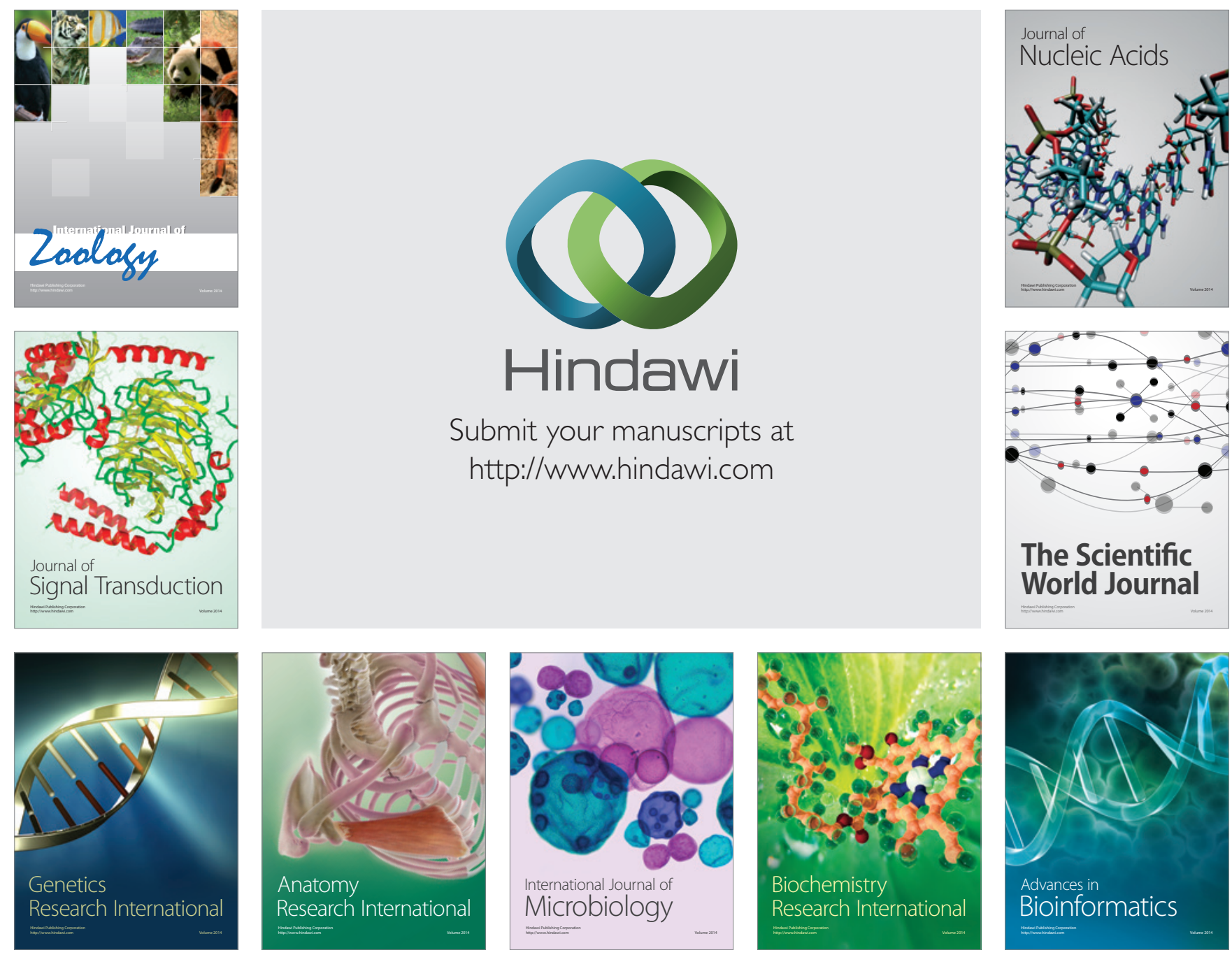

The Scientific World Journal
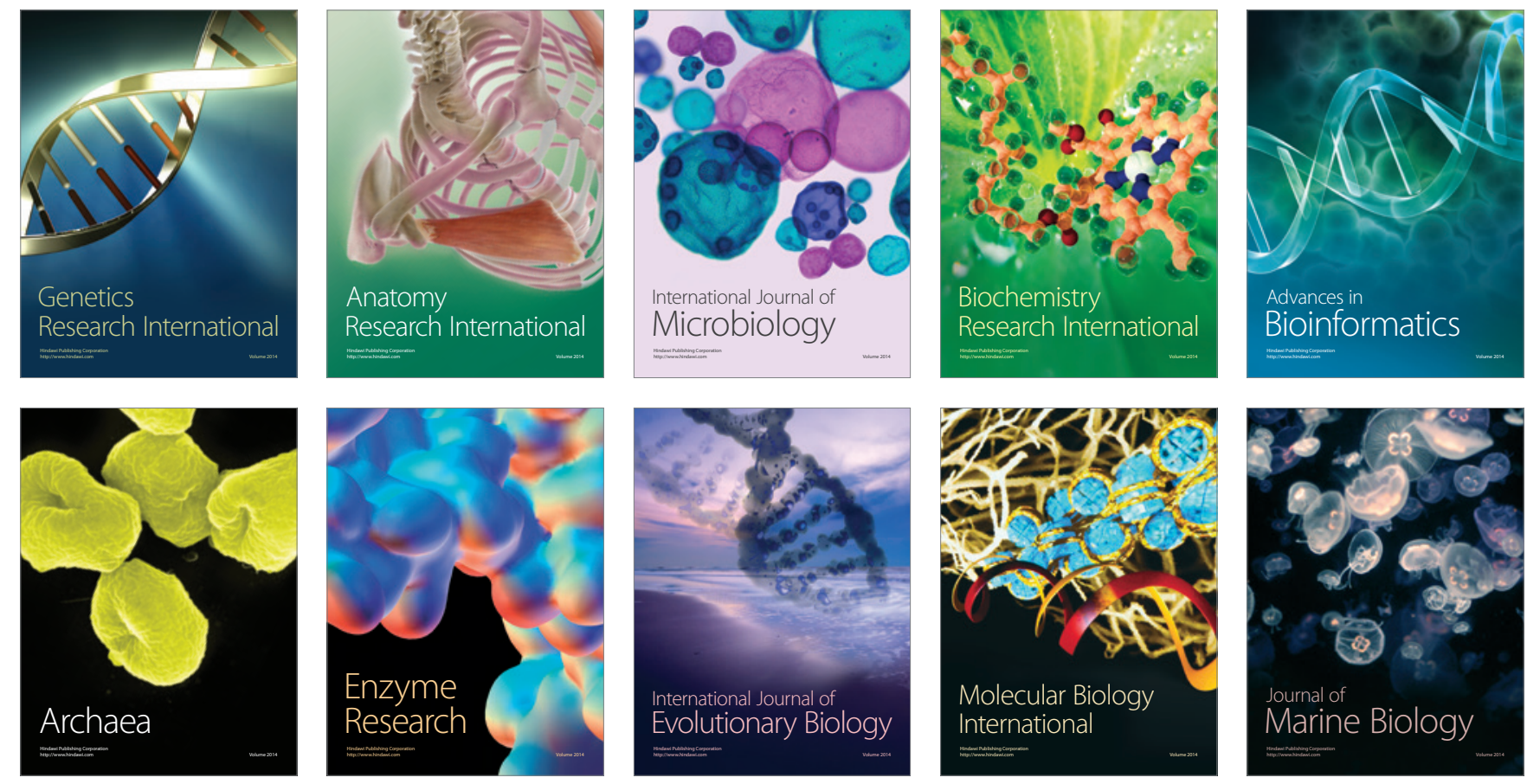